\title{
An Exploration of the Mechanism of Educational Scientific Decision-making in View of Bounded Rationality*
}

\begin{abstract}
ZHU Mei-xia
Henan university, Kaifeng, China

The scientific decision-making of education policies is not absolutely a complete rational process. The bounded rationality which takes rationality as the judgement standard is the essential connotation of the scientific decision-making of education policies. Therefore, based on this view and through shaping reasonable education policy values, this research gives full play to the driving force of educational scientific research on education policies and designs effective education decision-making information content and running agenda, thus optimizing the weigh principle of education policy proposals, advocating risk assessment and practice of education decisions, constructing institutional rationality of educational scientific decision-making, and finally realizing the rationality and scientificity of education policy decision-making.
\end{abstract}

Keywords: bounded rationality, education activity, education decision-making; exploration

\section{Introduction}

Educational scientific decision-making is a key factor concerning whether the education policy activities can duly run and gain good desired results or not. Thus, improving the scientificity of education policy decision-making is not just the initial premise and basis to make all important education policies, but also the important decision supporting and driving force to complete the task of education plans. Therefore, how to improve the scientificity, effectiveness and pertinence of education policy decision-making has become a major issue in the current education development strategy. It is generally acknowledged that "the ultimate goal of education decision-making comes down to the rational pursuit of education order" or in other words, the scientific decision-making of education policies must strictly follow the principle of absolute rationality. However, educational scientific decision-making activities are not absolutely rational activities, and whether the education decision-making is in a reasonable education interest weighing range or not is the intrinsic standard and basis to testify its scientificity.

Generally speaking, rationality refers to the rational characteristics which are subject to the social development law and presented on ideological behaviors, cognitive levels, and social practices of people who are in the social institution and adapted to socially recognized ideals, value pursuit and standard principles. This kind of characteristics is objective and also has a subjective initiative (Yang, 1999, pp. 34-38). After years' of research

\footnotetext{
* Acknowledgements: This paper is funded by the youth project of education of the National Social Science Foundation "Research on the value foundation of educational policy from the perspective of political philosophy" (CAA150123). ZHU Mei-xia, Master of Education, One classes of Chinese Teaching, School of Education, Henan university.
} 
and investigation, H.A. Simon, the founder of modern decision theory, creatively proposes bounded rationality theory, laying a foundation for modern decision theory. That is to say, bonded rationality theory holds that absolute "rational man" does not exist in the decision-making process, and only the "administrative man" with bounded rationality possesses the practical existence possibility and significance (Meng, 1999, pp. 69-75). Thus, the entire education policy activities show the main content of bounded rationality. The requirements of scientific decision-making are mainly manifested in two aspects: one is to "understand the various factors of decision-making as more as possible and estimate the possible outcomes and possibilities of every action programs as accurately as possible"; and the other is to "master decision-making principles and methods as proficiently as possible until discovering new principles and methods” (Meng, 1999, pp. 69-75). Similarly, whether the education policy decision-making which is filled up with education interests can base on the relative satisfaction degree and effectiveness of the many interested parties or not will determine the scientificity of education decision-making to the greatest extent, that is to say the educational scientific decision-making will not always realize its all intents, but can ensure the relative optimality of decision-making. Therefore, the study of educational scientific decision-making in the view of reasonable bounded rationality becomes particularly important. The scientization of education decision-making involves the scientization of education decision-making idea and technique (Zhang, Hu, \& Qu, 2009, pp. 138-158), so the educational scientific decision-making mechanism in the view of bounded rationality should include the following running principles and mechanisms.

\section{Shaping Reasonable Education Decision-making Values}

The essence of reasonable education decision-making is the central embodiment of intentionality, regularity and scientificity. The educational scientific decision-making cannot exhaust all the laws, and the principles it follows are as follows: firstly, the fundamental goal of education activities is to cultivate humans and promote human development and perfection. So human scale and factor are the primary premise and objective need to be concerned, and the law of human somatopsychic development will be an important basis and guidance to evaluate the scientificity of education decision-making and the proper meaning to reflect the perfection of personality, which also constitutes the value premise and logical starting point of the scientificity of education decision-making. Secondly, deeply understanding and complying with education development law and promoting the balanced development of education activities are the intrinsic requirement and necessary choice of educational scientific decision-making. Through reflecting education laws and pursing a reasonable and fair education order to standardize the education development direction, guide education practices and promote the perfection of education behaviors will become the main content of educational scientific decision-making. Thirdly, education, as an important part of the social system, shoulders the great responsibility of realizing social development; therefore, how to effectively promote the progress of social civilization and achieve the fair and justice values of social structure is a vital function of educational scientific decision-making. From the perspective public policy decision-making, educational scientific decision-making needs to comply with the social development law consciously, and thus settling current social issues, looking forward the education development blueprint and realizing the social values of scientific decision-making on the basis of summarizing the experiences of previous decision-making activities. 


\section{Giving Full Play to the Driving Force of Educational Scientific Research on Education Policies}

Scientific research is the theoretical foundation of all scientific decision-making activities. It is pointed out in Program for the Reform and Development of Education in China that, on the basis of fully understanding education development laws and combining education development practices at the present stage and the future developing trend, vigorously developing educational scientific research is a strong guarantee to improve the scientific level of education decision-making and promote education reform and development. National Education Plan further advocates to construct the educational consulting think tank with Chinese characteristics and strive to conduct pioneering and tactical education policy consulting studies, especially making studies concerning national overall development strategy and plan high on the agenda. Philosophy holds that understanding the world and changing the word are the two major themes of human activities, and science believes that the purpose of scientific research is scientific practice and application. Therefore, it is should thoroughly study education laws, sum up education experiences and answer significant theoretical and practical questions related to education reform and development by virtue of the power of research individuals and teams, and all these will converge on problematic consciousness and practical content relating to educational scientific decision-making. In nature, "education research is not essentially to self-fulfil and self-realize for a knowledge system, it is a kind of practical rationality based on the nature and foundation of education practices” (Yang, 2010, p. B1 ). Due to the limitation of researchers' knowledge and strength, this kind of practical rationality is a kind of "bounded rationality" substantially, and this valid scientificity based "bounded rationality" is one of the driving factors to realize the scientificity of education decision-making.

\section{Designing Effective Education Decision-making Information Content and Running Agenda}

System theory and information theory deem that the process of activities is an information circulating, feed backing and enriching process. As for the environment of education decision-making, the input, output, re-input, and re-output of information make the education decision-making process increasingly complex, so how to reasonably control the dynamic information, maintain the ecological balance of education decision-making and maximize its impact is an important topic. Educational scientific decision-making can make the decision-making information flow reasonably, and keep the transparency, openness and timeliness of information, avoiding unscientific problems like information asymmetry, malfunction and even faults effectively and improving the effectiveness and scientificity of education decision-making. The decision-making subjects need to constantly improve their information perceiving, obtaining and processing abilities, and on this basis, discover the current education contradictions, look into the potential education policy issues and proposes scientific countermeasure plans, particularly for those contradictions which are closely related to the education interests of the general public, and they should always maintain high waking consciousness and sharpness, make scientific decisions timely and defuse educational crises. Meanwhile, the value and function of consultants and executors in the decision-making process should be attached importance to. Education policy consulting is an important path and mechanism of the scientific decision-making of education policy, and as the subject, consultants are usually the group who pay attention to the running law and trend of education activities, their concerned and consulted 
contents are always closely associated with their own education interests. From the point of expressing their own education interests and on the basis of consulting, questioning and even criticizing, these consultants put forward opinions, suggestions and research achievements related to education policy decision-making, thus influencing the entire education decision-making process. Once brought into the scope of government education decision-making, education policy decision-making consulting will push the scientific advancement of education decision-making with its unique concerning effect and stress function. Therefore, paying attention to the education decision-making consulting mechanism plays an important supporting and securing role in improving the scientificity of education decision-making.

\section{Optimizing the Weigh Principle of Education Policy Proposals}

Science and public policy studies consider that the reasonable adjudication procedure and principle is a significant tool and method to ensure the scientific decision-making. The reference to modern scientific method and technology, the basis of policy adjudication principle and the form of a reasonable policy proposal adjudication procedure will largely ensure the realization of educational scientific decision-making. Aiming at the problems of excessive external cost and decision-making cost resulting from "strategic behavior", public choice theory develops two kinds of policy proposal adjudication principles: "demand-revealing process" and "voting against” (Mueller, 1992, pp. 70-81). The former is a process of selecting public resources in line with individual preference, and its essence lies in efficiently promoting individual choice on public resources through tax revenue collection to avoid high cost of decision-making and improve decision-making efficiency in essence; while the latter is a comparing and weighing program, the action is to weigh and balance according to its suggested various policy proposals and certain principle, and to successively screen out the policy proposals with a low level of reasonability and finally to choose the relatively best policy proposal by means of voting against. "Voting against" adjudication principle can effectively reduce "self-interest and self-concern" in decision-making process and improve the scientificity of education policy decision-making.

\section{Advocating Risk Assessment and Practice of Education Decisions}

Due to the constantly changing social environment and the complexity of education activities, education decision-making process involves many risk factors, and thus risk assessment and practice of education decisions have become an important part of educational scientific decision-making. Education decision-making risk analysis belongs to macro education decision-making behavior process. According to the requirement and standard of system theory and complex science, education decision-making risk analysis will make specific examinations and investigations on all the factors and causes in the complex system of education policy, and find out possible risk assumption and trend. The early evaluation on the implementation of education policies is the core issue of education policy risk analysis, this evaluation is based on the requirements of education activities and the practices of education policies, and its essence is to reduce adverse reactions in the process and further to optimize the efficiency of education policy implementation. That is to say, the analysis and evaluation by means of education decision-making risk can prevent policy crises in time, defuse potential policy risks and advance the scientificity of education decision-making. Meanwhile, relying only on decision-making risk analysis cannot resolve the risk factors of education decision-making completely, and that is why there is a need to establish and 
perfect an education decision-making risk prevention and error-correcting mechanism with education decision-making experiments as the core. Selecting pilots to conduct education policy experiments is one of the universal decision-making experiments now, and this method can correct education decision-making errors as early as possible. Besides, there are no successful precedents to follow for policy decision-making plans, especially new education decision-making plans, so the experiences, methods and efficiency of policy implementation can only be obtained and displayed in the process of policy experiments. Therefore, the policy experiment of education decision-making is not merely a critical path to maintain the sustainable and healthy implementation of education policies, but also the necessary requirement of educational scientific decision-making characterized by bounded rationality.

\section{Building the Institutional Rationality of Educational Scientific Decision-making}

Institutional rationality is the systemization, institutionalization and organization of rational value and principle. Educational scientific decision-making is a public policy decision-making behavior with rationality and availability as its goal, and institutional rationality is its important basis and guarantee. Generally, the subject and procedure of education decision-making is to "correctly balance the relation between the central and the local, the centralized management and decentralized management, the centralized decision-making and decentralized decision-making” (Yang, 2010, p. B1), and the essence is to well handle the relation between the centralized power and decentralized power in education decision-making, this handling of relations comes from the grasp of education decision-making pattern on rationality and the demarcation of the scope of bounded rationality.

One of the core issues of scientific decision-making theory is the problem of the relation between the centralized power and decentralized power which is particularly important in the field of education policy decision-making. Specifically, it needs to make clear and demarcate the reasonable distribution of specific decision-making content and information, namely which issues need to centralize power and which issues need to decentralize, or which issues need the combined effort of both etc. The essence of centralized power and decentralized power issue in the process of education decision-making is to solve the problem of efficiency and applicability, which will do great benefits to improve the scientificity of education decision-making.

However, the education policy problem is an unusually complex problem domain, it will be affected by various factors like the change of external social environment and the flow of internal environment. As a matter of fact, for decision-making, neither the centralized pattern nor the decentralized pattern can exhaust all the education policy issues. Hence, on the premise of constantly changing education decision-making environment at now and in the future, whether to centralize or to decentralize depends on the nature and feature of education decision-making issues, and the core issue in the process remains the applicability of decision-making methods. In some sense, the organic combination of these two decision-making patterns provides an effective institutional rationality guarantee for developing the scientific characters of education decision-making and further advancing the reasonable running of education policy activities.

\section{References}

Meng, F. H. (1999). Analysis on the nature and hierarchy of the scientificity of education decision-making. Journal of Beijing Normal University (Social Sciences), (4), 69-75.

Mueller, D. C. (1992). Public choice (C. Wang, Trans.) (pp. 70-81). Beijing: Commercial Press. 
Yang, Y. F. (2010). The scientific and democratic decisions: Analysis on the policy-setting process of National Plan for Medium and Long-Term Education Reform and Development (2010-2020). China Education Daily, 2010, November 16, p. B1.

Yang, Y. K. (1999). Rationality, non-rationality and reasonability-the conceptual foundation of scientific rationality. Studies in Philosophy of Science and Technology, (5), 34-38.

Zhang, X. L., Hu, X. J., \& Qu, Z. Y. (2009). Thoughts on decision-making mechanism for education policy based on a review of the development of education policy during the 30 years of reform. Journal of Tsinghua University (Philosophy and Social Sciences), (5), 138-158. 